\title{
USO DE INDICADORES BASEADOS NA LEGISLAÇÃO AMBIENTAL BRASILEIRA PARA ANÁLISE DE PROPRIEDADES RURAIS FAMILIARES DA AMAZÔNIA
}

\author{
USING INDICATORS BASED ON BRAZILIAN ENVIRONMENTAL LAWS FOR ANALYSIS OF \\ FAMILY FARMS IN THE AMAZON REGION
}

\author{
Diogo Feistauer ${ }^{1}$ Paulo Emilio Lovato ${ }^{2}$ Alexandre Siminski ${ }^{3}$ Augusto César da Costa Castilho ${ }^{4}$
}

\begin{abstract}
RESUMO
Os efeitos do novo Código Florestal Brasileiro (CFB) - Lei Federal n. 12.651 (BRASIL, 2012) - ainda estão sendo avaliados e discutidos quanto à adequação de propriedades rurais à legislação ambiental, tanto nas questões de recuperação de áreas degradadas quanto em relação às possibilidades de uso sustentável das áreas de preservação permanente (APP) e de Reserva Legal (RL). O objetivo do trabalho foi construir e aplicar indicadores ambientais de avaliação para verificar o desempenho ambiental de propriedades rurais familiares, considerando alternativas que o produtor deve seguir para se adequar às legislações ambientais e, também, verificando as condutas favoráveis ao não cometimento de infrações ou crimes ambientais. Foram estabelecidos indicadores ambientais de avaliação propostos a partir de parâmetros da legislação, os quais foram utilizados na análise de propriedades rurais conduzidas sob sistemas de produção orgânica (SPO) ou convencional (SPC). As propriedades rurais conduzidas em SPO apresentaram melhores resultados quanto aos indicadores ambientais de avaliação tanto das áreas de RL quanto das APPs, predominando o caráter essencialmente preservacionista nas propriedades rurais. Houve baixa ocorrência de casos de manejo agroflorestal ou agroextrativismo tanto nas áreas de RL quanto de APP das propriedades rurais avaliadas nos dois sistemas de produção. Os indicadores ambientais construídos a partir da legislação ambiental demonstraram ser uma ferramenta eficiente, prática e de baixo custo, para os técnicos e agricultores assim como na identificação de situações positivas de manejo em relação à adequação às leis ambientais.
\end{abstract}

Palavras-chave: indicadores ambientais; reserva legal; área de preservação permanente.

\section{ABSTRACT}

There is an ongoing discussion about the effects of the new Brazilian forestry code (BFC) - Federal Law \# 12.651 (BRASIL, 2012) - on the adequacy of small family farms, in terms of environmental degradation and recovery of forestry areas or regarding the possibilities of sustainable management of Permanent Preservation (PPA) or Legal Reserve (RL) areas. The aim of this work was to select and apply environmental evaluation indicators to analyze the environmental performance of small family farms, considering alternatives that the farmers should follow to comply with the laws and not to commit environmental crimes, in accordance with the Brazilian environmental legislation. We established environmental evaluation indicators taken from Brazilian environmental law parameters, which were tested in family farms with organic (SPO) or conventional (SPC) management systems. The organic family farms presented better results in terms

1 Engenheiro Agrônomo, MSc., Analista Ambiental do IBAMA na Gerência Executiva de Sinop, Rua das Castanheiras, 1297, Setor Comercial, CEP 79550-290, Sinop (MT), Brasil. dfeistauer@yahoo.com.br

2 Engenheiro Agrônomo, Dr., Professor do Curso de Agronomia e do Programa de Mestrado em Agroecossistemas e Doutorado em Recursos Genéticos Vegetais, Rod. Ademar Gonzaga, 1346, Itacorubi, CEP 88034-102, Florianópolis (SC), Brasil. paulo.lovato@ufsc.br

3 Engenheiro Agrônomo, Dr., Professor da Universidade Federal de Santa Catarina, Campus de Curitibanos e pesquisador do Núcleo de Pesquisas em Florestas Tropicais, Centro de Ciências Agrárias, Universidade Federal de Santa Catarina, Rod. Ulisses Gaboardi, Km 3, CEP 89520-000, Curitibanos (SC), Brasil. siminski@cbs.ufsc.br

4 Biólogo, MSc., Analista Ambiental do IBAMA da Superintendência em Cuiabá, Av. Historiador Rubens de Mendonça, 5350, Bairro Morada da Serra, CEP 78055-900, Cuiabá (MT), Brasil. gutocastilho@gmail.com

Recebido para publicação em 30/10/2013 e aceito em 8/05/2015

Ci. Fl., v. 27, n. 1, jan.-mar., 2017 
of environmental evaluation indicators, either on APP or on RL areas Preservationist management was predominat on LR and on APP, in organic and in conventional production systems, and there were only a few occurrences of agroforestry systems or non-timber forest managements. The environmental evaluation indicators designed from aspects of Brazilian environmental law showed to be an efficient, practical and inexpensive tool to help technicians and farmers to identify positive situations of compliance to Brazilian environmental laws.

Keywords: environmental indicators; legal reserve; permanent preservation areas.

\section{INTRODUÇÃO}

A legislação ambiental é considerada um importante instrumento jurídico de prevenção de danos ambientais e condução de pessoas e estados para a adoção de práticas ambientalmente mais sustentáveis, sobretudo na Amazônia brasileira (D'ANTONA; VANWEY; LUDEWIGS, 2011). A Lei Federal n. 12.651 (BRASIL, 2012) definiu que as áreas de reserva legal (RL) possuem a função de assegurar o uso econômico de modo sustentável dos recursos naturais do imóvel rural, auxiliar a conservação e a reabilitação dos processos ecológicos e promover a conservação da biodiversidade, bem como o abrigo e a proteção de fauna silvestre e da flora nativa.

Além disso, também de acordo com esta Lei, as áreas de preservação permanente (APPs) possuem a função de preservar os recursos hídricos, a paisagem, a estabilidade geológica e a biodiversidade, facilitar o fluxo gênico de fauna e flora, proteger o solo e assegurar o bem-estar das populações humanas. A maior ocorrência de APPs em propriedades rurais compõe-se de margens de córregos, nascentes e topos de morros (JACOVINE et al., 2008; OLIVEIRA et al., 2008). Os limites dessas áreas estão determinados pelo novo Código Florestal e variam em função da largura dos rios e, no caso de recuperação de áreas degradadas, em função do tamanho da propriedade rural.

Para muitos agricultores e técnicos, as áreas de RL e APP apresentam caráter essencialmente preservacionista, uma vez que não são vistas como áreas passíveis de serem utilizadas de forma produtiva (MOONEN; BARBIERI, 2008). Desta maneira, tornam-se necessárias pesquisas focadas às propostas de modelos agrícolas e do uso da terra com foco na sustentabilidade do agroecossistema, que estejam em consonância com a legislação ambiental, no sentido de reconciliar agricultura e questões ambientais, excluindo os agricultores da situação de marginalidade imposta pela inadequação à legislação ambiental, bem como incluí-los nas políticas públicas para a região amazônica (GARBIN et al., 2006; PETTERSEN; VON DER WEID; FERNANDES, 2009; FEISTAUER, 2014). Adotou-se neste trabalho o conceito de Agroecossistemas, proposto por Conway (1987) de sistemas ecológicos modificados pela ação humana para a produção de alimentos, fibras e outros produtos agrícolas ou florestais.

A integração entre a conservação e utilização da agrobiodiversidade com enfoque agroecológico são componentes importantes das políticas públicas para a agricultura sustentável no Brasil, que hoje reconhece a possibilidade de manejos conservacionistas ou sistemas agroflorestais (SAFs) nas áreas de RL (MACHADO; SANTILI; MAGALHÃES, 2008), a exemplo da Lei Federal nº 12.854 (BRASIL, 2013), que autoriza SAFs em áreas degradadas.

Apesar da existência dessas possibilidades, ainda são poucas as áreas manejadas com esse foco, principalmente devido à dificuldade de interpretação ou mesmo compreensão da legislação ambiental, em particular por parte daqueles agricultores não assessorados por apoio técnico especializado que os conduzam em uma estratégia de gestão e manejo da propriedade rural com foco na adequação à legislação ambiental (MEIRELLES FILHO, 2006).

Assim, surgem questões pertinentes como: Qual o potencial de uso agrícola das áreas de preservação permanente e reserva legal? Qual a maneira de avaliar a adequação à legislação ambiental de forma a engajar técnicos e agricultores nesse processo?

Para tentar responder a essas perguntas, o presente trabalho propôs o desenho de indicadores de avaliação ambiental que possam ser utilizados como ferramenta metodológica para orientar produtores e técnicos no processo de adequação à legislação ambiental das propriedades rurais.

Os indicadores ambientais são atributos mensuráveis através dos quais se pretende obter informação sobre fenômenos de relevância que permitem descrever ou valorar mudanças nas condições ambientais 
(HEINK; KOWARIK, 2010), sendo que o esforço das instituições tem sido em construir indicadores simples de serem aplicados e que não percam a capacidade de abordarem as relações presentes no ambiente (FREITAS et al., 2013). Neste sentido, indicadores devem ser aplicáveis a grande número de ecossistemas, de fácil medição permitindo à população local participar do procedimento, devem ser sensíveis às mudanças do sistema, permitir o cruzamento com outros indicadores e representar os padrões de sustentabilidade (FERRAZ, 2003).

A utilização de bons indicadores permite o monitoramento a baixo custo, a possibilidade de mensuração de processos em escala temporal e espacial, de fácil identificação das causas de degradação ambiental e de potenciais para a sustentabilidade do agroecossistema (SARADÓN; FLORES, 2009).

Diante destes aspectos procurou-se desenhar indicadores ambientais de avaliação para verificar o desempenho ambiental de propriedades rurais familiares considerando alternativas que o produtor deve seguir para se adequar às legislações ambientais, sobretudo ao novo Código Florestal (Lei n. 12.651) (BRASIL, 2012), procurando verificar as condutas favoráveis ao não cometimento de infrações ou crimes (Lei Federal n. 9.605) (BRASIL, 1998).

Os indicadores foram testados em pequenas propriedades rurais conduzidas sob sistemas de produção orgânico (SPO) e convencional (SPC), com o objetivo de avaliar o estado de adequação à legislação ambiental e também verificar o uso que os produtores aplicam às áreas de RL e APP de suas propriedades.

\section{MATERIAIS E MÉTODOS}

A pesquisa foi realizada em dezessete pequenas propriedades rurais familiares dos municípios de Nova Santa Helena, Matupá, Terra Nova do Norte, e Guarantã do Norte, pertencentes ao território Portal da Amazônia - MT (GARBIN et al., 2006), norte do Mato Grosso (Figura 1).

O Bioma é Amazônia, com vegetação típica do tipo Floresta Ombrófila Aberta, caracterizada por

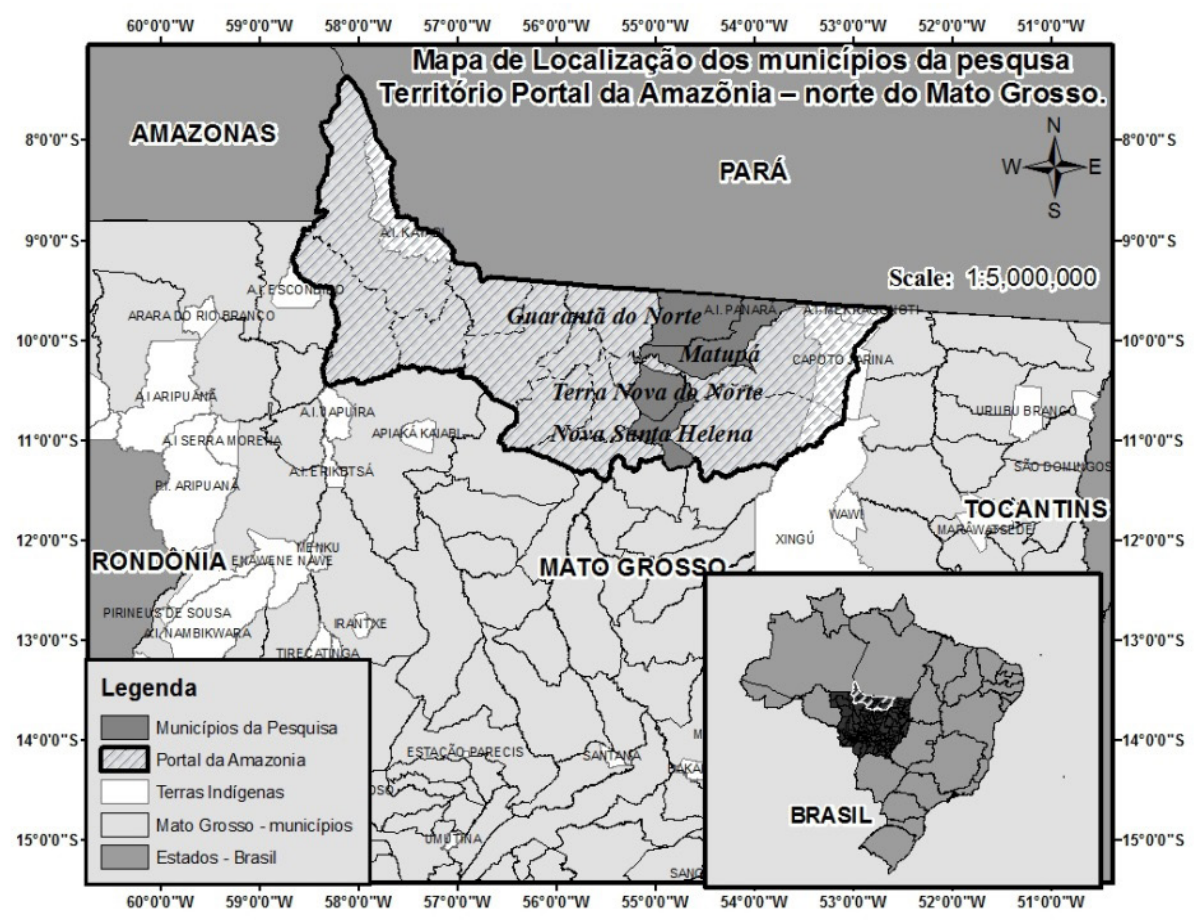

FIGURA 1: Mapa do Território Portal da Amazônia - MT com a localização dos municípios de Terra Nova do Norte, Guarantã do Norte, Matupá e Nova Santa Helena.

FIGURE 1: Map of Portal da Amazônia Territory, Mato Grosso state, showing the municipalities of Terra Nova do Norte, Guarantã do Norte, Matupá and Nova Santa Helena. 
fisionomia florestal de árvores mais espaçadas e extrato arbustivo pouco denso (IBGE, 2010). A altitude média da região é de $380 \mathrm{~m}$ em relação ao nível do mar, com relevo plano a suavemente ondulado. Os solos são formados por rochas sedimentares, em geral do grupo dos latossolos vermelho amarelo, distróficos, com médios teores de argila (IBGE, 2011). A classificação climática de acordo com Koeppen é do tipo $\mathrm{Aw}$ - tropical com estação seca no inverno - temperatura média anual acima de $25^{\circ} \mathrm{C}$ e precipitações médias anuais em torno de 2100 a 2400 milímetros anuais (IBGE, 2010).

Em função da representatividade que as propriedades rurais de agricultura familiar possuem no Estado do Mato Grosso e no território Portal da Amazônia, respectivamente 76\% e 83\%, conforme dados do Censo Agropecuário (IBGE, 2006) foram escolhidas propriedades rurais consideradas típicas para a região Norte do Mato Grosso, com produção agropecuária baseada na pastagem para pecuária de leite e de corte, fruticultura, horticultura e criação de pequenos animais.

Todas as propriedades rurais avaliadas são enquadradas como agricultura familiar pela Lei Federal $\mathrm{n}^{\mathrm{o}} 11.326$ de 2006, a partir dos seguintes critérios: i) área menor que quatro módulos fiscais - considerando que, nos municípios avaliados, um módulo fiscal representa 90 hectares; ii) família de produtores rurais residentes e com a maior parte da renda oriunda de sua propriedade rural), e iii) produtores filiados a cooperativas ou a projetos de desenvolvimento rural junto às prefeituras municipais.

As propriedades rurais foram classificadas em dois grupos. O primeiro grupo foi formado por nove propriedades conduzidas em sistema de produção orgânica (SPO), certificadas desde o ano de 2004 por uma empresa certificadora registrada no Ministério da Agricultura, Pecuária e Abastecimento (MAPA), a partir das normas brasileiras de agricultura orgânica estabelecidas na Lei Federal n. 10.831, (BRASIL, 2003) (Normas Brasileiras de Agricultura Orgânica). As nove propriedades rurais avaliadas representaram um universo amostral de $40 \%$ das propriedades rurais registradas como tal em uma cooperativa. As principais atividades agrícolas presentes são o guaraná (Paulinia cupania), mandioca (Manihot esculenta), café (Coffea canephora), caju (Anacardium occidentale), cupuaçu (Theobroma grandiflorum), legumes e verduras para a comercialização nos mercados institucionais e feiras municipais, gado para a produção de leite e corte.

O segundo grupo de propriedades foi formado por oito propriedades conduzidas em sistema de produção convencional (SPC), ou seja, por produtores não certificados (orgânicos) e que não se declararam ecológicos. Tais propriedades foram escolhidas pela localização adjacente ou próximas das conduzidas com SPO. Isso significa que são propriedades rurais pertencentes à mesma microbacia hidrográfica, com relevo e paisagem semelhantes e mesmo tipo de floresta nativa típica, porque, segundo Kuiper (2000), tal estratégia de análise de propriedades adjacentes permite minimizar o erro amostral na avaliação dos dois sistemas de produção.

A principal atividade do SPC é a produção de gado de corte, e algumas atividades destinadas para o consumo familiar, como verduras, hortaliças e fruticultura em quintais agroflorestais. Evidenciase claramente o maior grau de diversificação de atividades agrícolas nas propriedades rurais em sistema orgânico de produção, em relação ao sistema de produção convencional (SPC), o qual, por outro lado, apresenta menor número de atividades desenvolvidas e as existentes são conduzidas com uso de insumos químicos e agrotóxicos.

\section{Seleção de indicadores ambientais de avaliação a partir da legislação ambiental brasileira.}

A seleção dos indicadores ambientais de avaliação foi feita a partir de adaptação da metodologia denominada Marco de Avaliação de Sistemas de Manejo dos Recursos Naturais Incorporando Indicadores de Sustentabilidade (MESMIS) - (LÓPEZ-RIDAURA; MASERA; ASTIER, 2002). Essa metodologia permite construir e desenhar indicadores de sustentabilidade para a avaliação de sistemas produtivos em diferentes realidades e agroecossistemas, mediante um roteiro metodológico com etapas sequenciais de análise que convergem para a escolha de um conjunto de indicadores adequados ao contexto particular.

Primeiramente, procurou-se caracterizar a região e os locais da pesquisa na escala espacial, temporal, características socioambientais e com relação à legislação ambiental. Com essas informações foi possível definir os pontos críticos, que servem para identificar as vulnerabilidades das unidades de análise. Em geral, os pontos críticos estão relacionados aos atributos gerais dos sistemas sustentáveis, como resiliência, 
produtividade, adaptabilidade ou estabilidade (LÓPEZ-RIDAURA; MASERA; ASTIER, 2002).

$O$ ponto crítico utilizado relaciona-se aos aspectos da legislação ambiental brasileira, sobretudo às condutas que podem incorrer em infrações ou crimes aos agricultores, de acordo com a Lei dos Crimes Ambientais (Lei Federal n. 9.605) (BRASIL, 1988). Os pontos críticos relacionados aos aspectos ambientais, socioeconômicos e culturais são inerentes ao modelo agrícola da região, aos recursos naturais e aos aspectos sociais e culturais. Nesse grupo de pontos críticos, o principal elemento identificado foi o processo de degradação ambienta, consequência da expansão das áreas desflorestadas nas propriedades da região, com vistas à expansão da área de pastagem para a produção pecuária (ARVOR et al., 2011; MEIRELHES FILHO, 2006; MENDES et al., 2011).

Muitos são os aspectos e exigências impostas para as propriedades rurais quanto à adequação da legislação ambiental brasileira. Entretanto, para a escolha dos pontos críticos foram considerados os aspectos da legislação mais diretamente relacionados com a gestão e manejo das propriedades, especificamente as relacionadas com as áreas de RL, APP, sobretudo aos aspectos da Lei Federal n. 9.605 (BRASIL, 1988) e a Lei Federal n. 12.651 (BRASIL, 2012). As definições sobre a função ambiental e ecológica destas

TABELA 1: Definições de funções ecológicas e ambientais das áreas de preservação permanente (APP) e reserva legal (RL), segundo a legislação ambiental brasileira.

TABLE 1: Definitions of ecological and environmental functions [of permanent preservation areas (APP) and legal reserve $(\mathrm{RL})]$ according to Brazilian environmental laws.

\begin{tabular}{|c|c|c|c|}
\hline Área & Função Ecológica e Ambiental & Referência Legal & Pontos Críticos \\
\hline APP & $\begin{array}{l}\text { - Preservar os recursos hídricos, a } \\
\text { paisagem, a estabilidade geológica e a } \\
\text { biodiversidade, facilitar o fluxo gênico da } \\
\text { fauna e flora, bem como proteger o solo } \\
\text { e assegurar o bem-estar das populações } \\
\text { humanas. } \\
\text { - Conter a erosão do solo e mitigar riscos } \\
\text { de enchentes e deslizamentos; proteger } \\
\text { as várzeas, as restingas ou veredas; } \\
\text { abrigar exemplares da fauna ou da flora } \\
\text { ameaçados de extinção; proteger sítios } \\
\text { de excepcional beleza ou valor científico, } \\
\text { cultural ou histórico; formar faixas de } \\
\text { proteção ao longo de rodovias e ferrovias; } \\
\text { assegurar condições de bem-estar público; } \\
\text { auxiliar a defesa do território nacional; } \\
\text { proteger áreas úmidas, especialmente as } \\
\text { de importância internacional. }\end{array}$ & $\begin{array}{l}\text { - Lei Federal n. } \\
12.651 \\
\text { (BRASIL, 2012) } \\
\text { (Cód. Florestal); } \\
\text { - Lei Federal n. 9.605 } \\
\text { (BRASIL, 1998) } \\
\text { (Lei de crimes } \\
\text { ambientais); } \\
\text { - Decreto Federal n. } \\
\quad 6.514 \\
\text { (BRASIL, 2008). }\end{array}$ & $\begin{array}{l}\text { - Dano em floresta considerada de } \\
\text { preservação permanente, mesmo que } \\
\text { em formação. } \\
\text { - Corte de árvores em floresta } \\
\text { considerada de preservação } \\
\text { permanente. } \\
\text { - Extração mineral em floresta } \\
\text { considerada de preservação } \\
\text { permanente. } \\
\text { - Impedir ou dificultar a regeneração } \\
\text { natural de florestas de áreas de } \\
\text { preservação permanente. } \\
\text { - Manutenção permanente de animais } \\
\text { domésticos no interior das áreas de } \\
\text { preservação permanentes. }\end{array}$ \\
\hline $\mathrm{RL}$ & $\begin{array}{l}\text { - Assegurar o uso econômico de modo } \\
\text { sustentável dos recursos naturais do } \\
\text { imóvel rural, auxiliar a conservação } \\
\text { e a reabilitação dos processos } \\
\text { ecológicos e promover a conservação } \\
\text { da biodiversidade, bem como o abrigo e } \\
\text { a proteção de fauna silvestre e da flora } \\
\text { nativa. } \\
\text { - Formar corredores ecológicos com } \\
\text { outras áreas legalmente protegidas, } \\
\text { sejam elas outra reserva legal, área de } \\
\text { preservação permanente ou unidades de } \\
\text { conservação. }\end{array}$ & $\begin{array}{l}\text { - Lei Federal n. } \\
12.651 \\
\text { (BRASIL, 2012). } \\
\text { (Cód.Florestal); } \\
\text { - Lei Federal n. 9.605 } \\
\text { (BRASIL, 1998) } \\
\\
\text { (Lei de crimes } \\
\text { ambientais); } \\
\text { - Decreto Federal n. } \\
\text { 6.514 } \\
\text { (BRASIL, 2008). }\end{array}$ & $\begin{array}{c}\text { - Desmate, destruição, dano ou } \\
\text { queima na área de reserva legal; } \\
\text { - Impedir ou dificultar a regeneração } \\
\text { natural da área de reserva legal; } \\
\text { - Exploração não autorizada na área } \\
\text { de reserva legal. }\end{array}$ \\
\hline
\end{tabular}


áreas foram obtidas a partir das descrições na legislação ambiental brasileira em vigor, além disso, foram definidas práticas que impedem a manutenção da função ecológica desses espaços e que são consideradas infrações e crimes pela legislação ambiental brasileira (Tabela 1).

\section{Escolha dos Indicadores Ambientais de Avaliação.}

Os indicadores ambientais de avaliação e os seus referenciais foram escolhidos em função dos pontos críticos e dos aspectos da legislação ambiental vigente (Tabela 2). A construção desses referenciais foi realizada mediante análise de quais situações desejadas e as indesejáveis (quanto à adequação à legislação ambiental) nas APP e RL das propriedades rurais.

Além disso, foram utilizados alguns princípios norteadores recomendados pela Organização das Nações Unidas para Alimentação e Agricultura - FAO (2010) e sugeridos como situações ideais em termos de sustentabilidade em agroecossistemas em processo de transição ecológica, como o uso de adubação orgânica, adubação verde, rotação de culturas, uso de insumos agrícolas locais, uso mínimo de substâncias tóxicas ou poluentes, aumento da cobertura do solo e manter uma alta diversidade genética procurando beneficiar os processos ecológicos promovidos por esta biodiversidade.

$\mathrm{Na}$ escolha dos referenciais levou-se em consideração aspectos como a literatura científica, o conhecimento técnico local, o conhecimento dos agricultores (SARANDÓN; FLORES, 2009), bem como dos referenciais da legislação ambiental vigente, como leis, decretos, instruções normativas e resoluções do Conselho Nacional Do Meio Ambiente.

\section{Avaliação da adequação ambiental das propriedades rurais}

Os indicadores ambientais de avaliação foram estimados nas áreas de RLe APP das propriedades rurais do SPO e SPC. Cada propriedade rural foi percorrida por caminhamento, sendo registradas coordenadas geográficas dos limites e pontos de referência para o cálculo da área total e das áreas de RL e APP.

As coletas dos dados foram realizadas em parcelas retangulares de $10 \times 50 \mathrm{~m}\left(500 \mathrm{~m}^{2}\right)$ nas áreas de RL (demarcadas no sentido Norte-Sul) escolhidas aleatoriamente no maciço florestal avaliado. Para as APPs, as avaliações foram em parcelas de $10 \times 20 \mathrm{~m}\left(200 \mathrm{~m}^{2}\right)$, com demarcações feitas a partir de cinco metros da margem do rio ou córrego existente, seguindo-se esta margem até completar $20 \mathrm{~m}$, ou seja, considerando que a largura mínima de APP em margens de córregos ou rios é de $30 \mathrm{~m}$, a amostragem enquadra-se totalmente inserida nessa área.

O número de parcelas para cada propriedade rural foi determinado a partir da área total dos fragmentos florestais remanescentes, de forma que o número de parcelas completasse uma intensidade de amostragem de um mínimo de $5 \%$ da área total dos fragmentos florestais existentes; percentagem esta respeitada tanto para as áreas de RL quanto de APP. Esse percentual é considerado suficiente para amostragens aleatórias de acordo com estudos feitos por Ubialli et al. (2009) na região norte do Estado do Mato Grosso. Os fragmentos florestais foram previamente quantificados em laboratório com o uso de imagens de satélite e programa de sistema de informação geográfica software ArcGis - versão 9.1.

A sistemática de avaliação in loco foi realizada por meio de caminhamento ou varredura, seguido pelo registro dos dados de cada um dos indicadores ambientais de avaliação. Nos fragmentos de RL, as avaliações foram registradas a cada 10 metros de caminhamento na parcela, ou seja, percorrendo-se cinco subáreas de $100 \mathrm{~m}^{2}$. No caso das APPs, as avaliações foram registradas a cada cinco metros de caminhamento, em quatro subáreas de $50 \mathrm{~m}^{2}$. O objetivo desse procedimento (subparcelas) foi evitar erros aleatórios nos casos em que apenas um percentual da parcela apresente o referencial do indicador ambiental de avaliação analisado.

\section{Análises estatísticas}

Os dados coletados através da avaliação com os indicadores ambientais foram sistematizados e analisados da seguinte maneira: os indicadores número de árvores cortadas e número de árvores com $\mathrm{DAP}>40 \mathrm{~cm}$ foram testados com o teste paramétrico $t$-student. Os demais dados foram analisados pelo teste 
TABELA 2: Lista de indicadores ambientais de avaliação relacionados aos pontos críticos e referenciais para avaliação das unidades de análise (áreas de preservação permanente - APP; reserva legal - RL) de pequenas propriedades rurais do Território Portal da Amazônia - Mato Grosso.

TABLE 2: List of environmental evaluation indicators related to critical parameters and references to evaluate the forestry fragments (Permanent preservation areas - APP, and Legal Reserve RL) on small family farms on Portal da Amazônia territory, Mato Grosso state.

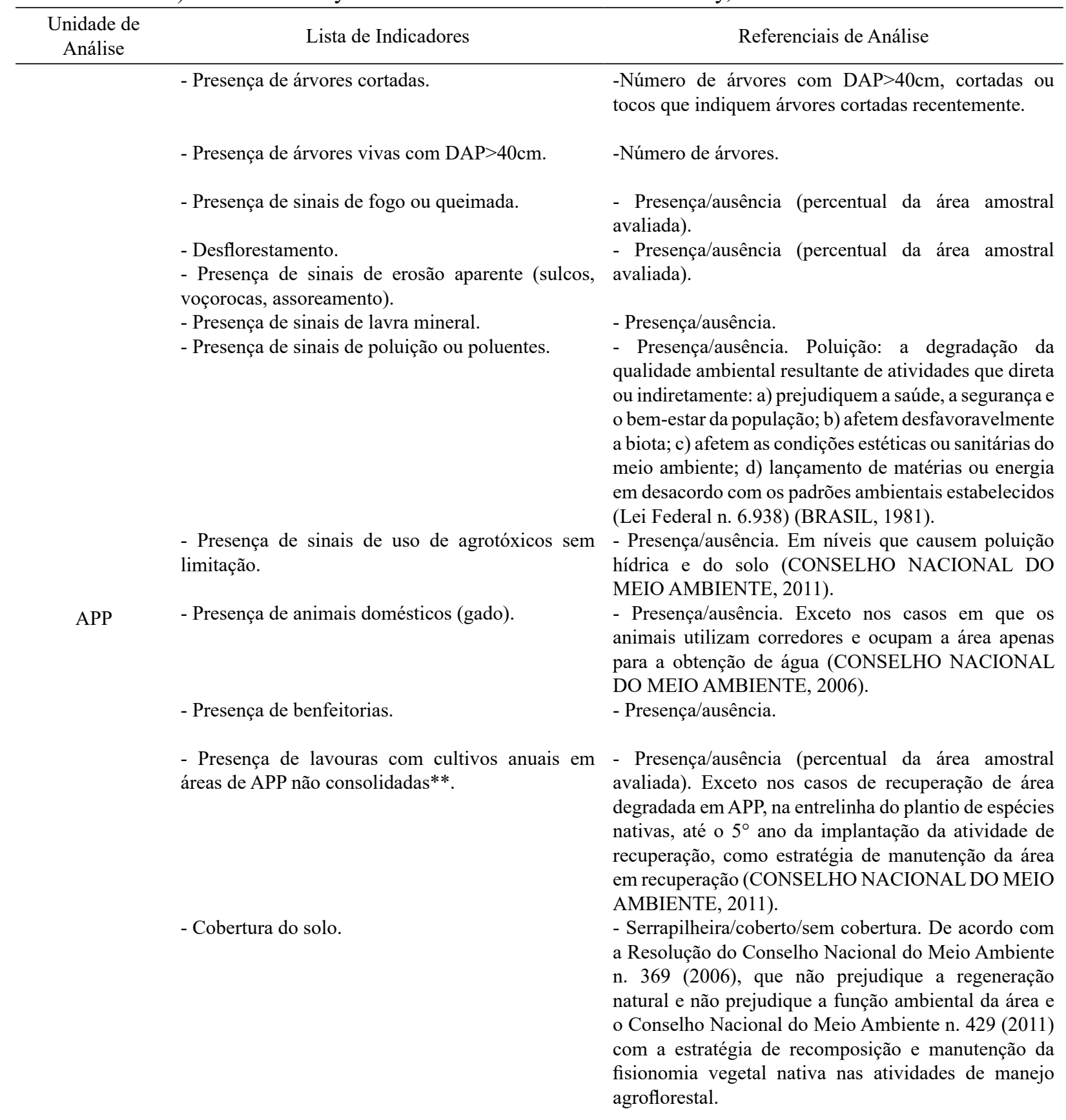


TABELA 2: Continuação...

TABLE 2: Continued...

\begin{tabular}{|c|c|c|}
\hline $\begin{array}{l}\text { Unidade de } \\
\text { Análise }\end{array}$ & Lista de Indicadores & Referenciais de Análise \\
\hline RL & $\begin{array}{l}\text { - Presença de árvores cortadas (tocos) }{ }^{* * *} \text {. } \\
\text { - Presença de árvores vivas com DAP }>40 \mathrm{~cm} \text {. } \\
\text { - Presença de sinais de fogo ou queimada. } \\
\text { - Desflorestamento. } \\
\text { - Presença de sinais de poluição ou poluentes na } \\
\text { RL. } \\
\text { - Presença de sinais de uso de agrotóxicos sem } \\
\text { limitação. } \\
\text { - Tipo de intervenção ou manejo dado às espécies } \\
\text { arbóreas da RL. } \\
\text { - Tipo de intervenção ou manejo dado aos produtos } \\
\text { não madeireiros da RL. }\end{array}$ & $\begin{array}{l}\text {-Árvores dom DAP }>40 \mathrm{~cm} \text {, cortadas ou tocos que } \\
\text { indiquem árvores cortadas recentemente. } \\
\text { - Presença/ausência. } \\
\text { - Presença/ausência (percentual da área amostral } \\
\text { avaliada). } \\
\text { - Presença/ausência (percentual da área amostral } \\
\text { avaliada). } \\
\text {-Em níveis que causem poluição hídrica e do solo (Lei } \\
\text { Federal 9.605) (BRASIL, 1998). } \\
\text {-Em níveis que causem poluição hídrica e do solo (Lei } \\
\text { Federal 9.605) (BRASIL, 1998). } \\
\text { - Sistemas agroflorestais (SAF) ou manejo florestal } \\
\text { sustentável, que não descaracterizem a função } \\
\text { ecológica e ambiental da área. } \\
\text { - SAF/Manejo Florestal Sustentável de produtos não } \\
\text { madeireiros ou madeireiros/não há manejo/outro tipo } \\
\text { de manejo. }\end{array}$ \\
\hline
\end{tabular}

Em que: * Foram considerados os pontos críticos não autorizados pelo órgão ambiental competente e considerados infrações pela legislação ambiental brasileira; ** Conforme o Conselho Nacional Do Meio Ambiente n. 425 (2010); *** Corte de árvores acima de $15 \mathrm{~m}^{3}$ /ano para lenha ou uso doméstico dentro dos limites de retiradas estabelecidos no art. 56 da Lei Federal n. 12.651 (BRASIL, 2012).

Qui-Quadrado (FERNANDES, 1999).

\section{RESULTADOS E DISCUSSÃO}

\section{Avaliação da adequação ambiental das propriedades rurais}

\section{Adequação ambiental das APPs}

Seguindo o critério de intensidade amostral, foram avaliadas 89 parcelas no SPO e 121 parcelas no SPC, valores que indicam estado de menor fragmentação e remanescentes florestais mais homogêneos nas margens dos córregos no SPO. Os indicadores ambientais de avaliação relacionados ao uso conservacionista da APP: árvores cortadas; frequência absoluta de árvores cortadas e árvores com DAP $>40 \mathrm{~cm}$ apresentaram valores muito baixos, sem diferenças significativas entre os dois sistemas de produção avaliados (Tabela 3). Essa situação está provavelmente relacionada ao caráter preservacionista dado pelos agricultores aos fragmentos florestais na APP, nos quais há pouca ocorrência de manejo produtivo na forma de sistemas agroflorestais, agroextrativismo ou mesmo simples coleta para uso próprio de produtos florestais madeireiros e não madeireiros.

A frequência absoluta deárvores DAP $>40 \mathrm{~cm}$ (compotencial de manejo florestal) foi significativamente maior nas propriedades em SPO; porém, não foram encontrados sinais de nenhum tipo de manejo feito sobre estas árvores. De acordo com a legislação ambiental, as APPs são passíveis de intervenção e manejo nas propriedades de agricultores familiares, desde que não descaracterizem a cobertura vegetal, bem como não comprometam a estabilidade das encostas e margens dos corpos de água, corredores de fauna, drenagem e os cursos de água intermitentes, manutenção da biota e a qualidade das águas de uma maneira geral (CONSELHO NACIONAL DO MEIO AMBIENTE, 2006; 2010; 2011), ou nos casos de interesse social de baixo impacto ambiental estabelecido no novo Código Florestal (Lei Federal no 12.651) (BRASIL, 2012).

Apesar desta possibilidade posta pela legislação ambiental brasileira, a maior parte dos produtores 
TABELA 3: Resultados das médias dos indicadores ambientais de avaliação para as áreas de preservação permanente (APP) em dois sistemas de produção: orgânico e convencional, de propriedades rurais familiares do Território Portal da Amazônia, Mato Grosso.

TABLE 3: Average results from the environmental evaluation indicators for the permanent preservation areas evaluation on both production systems: organic (SPO) and conventional (SPC) on small family farms at Portal da Amazônia territory, Mato Grosso state.

\begin{tabular}{|c|c|c|c|c|}
\hline \multirow{2}{*}{\multicolumn{2}{|c|}{ Indicadores Ambientais de Avaliação (média/ha de APP) }} & \multicolumn{2}{|c|}{ Sistemas de Produção } & \multirow[b]{2}{*}{ Sig.* } \\
\hline & & $\begin{array}{l}\text { Orgânico } \\
\text { (SPO) }\end{array}$ & $\begin{array}{c}\text { Convencional } \\
\text { (SPC) }\end{array}$ & \\
\hline \multicolumn{2}{|l|}{ Árvores cortadas (n.) } & 0,6 & 0,0 & n.s \\
\hline \multicolumn{2}{|c|}{ Frequência absoluta - (parcelas com árvores cortadas, \%) } & 1,1 & 0,0 & n.s \\
\hline \multicolumn{2}{|c|}{ Árvores com DAP $>40 \mathrm{~cm}\left(\mathrm{n}^{\circ}\right)$} & 28 & 24 & n.s \\
\hline \multicolumn{2}{|c|}{ Frequência absoluta (parcelas com árvores DAP $>40$ cm, \%) } & 34 & 21 & sig. \\
\hline \multicolumn{2}{|c|}{ Sinais de fogo ou queimadas recentes (n. $\left.{ }^{\circ}\right)$} & 0,02 & 0,0 & n.s \\
\hline \multicolumn{2}{|c|}{ Desflorestamento (área desflorestada, ha) } & 0,3 & 0,6 & sig. \\
\hline \multicolumn{2}{|c|}{ Sinais aparentes de erosão, voçoroca ou assoreamento (ha) } & 0,1 & 0,2 & sig. \\
\hline \multicolumn{2}{|l|}{ Sinais de lavra mineral (ha) } & 0,0 & 0,0 & n.s. \\
\hline \multicolumn{2}{|c|}{ Sinais de poluentes ou poluição (há) } & 0,0 & 0,0 & n.s. \\
\hline \multicolumn{2}{|c|}{ Sinais do uso de agrotóxicos (ha) } & 0,0 & 0,0 & n.s. \\
\hline \multicolumn{2}{|c|}{ Presença permanente de animais domésticos (gado) - (ha) } & 0,2 & 0,6 & sig. \\
\hline \multicolumn{2}{|c|}{ Presença de benfeitorias (presença/ausência) } & 0,0 & 0,0 & n.s. \\
\hline \multicolumn{2}{|c|}{ Presença de lavouras com cultivos anuais (ha) } & 0,2 & 0,4 & sig. \\
\hline \multirow{3}{*}{ Cobertura do solo (ha) } & Coberto & 0,27 & 0,46 & sig. \\
\hline & Exposto & 0,03 & 0,09 & sig. \\
\hline & Serrapilheira & 0,70 & 0,45 & sig. \\
\hline
\end{tabular}

Em que: * Significância do teste estatístico - médias dos indicadores ambientais de avaliação seguidos de "n.s." não diferem entre si, e seguidos de "sig." diferem entre si, pelo teste Qui-Quadrado em nível de significância de 5\% de probabilidade, à exceção dos indicadores "Árvores cortadas com DAP $>40 \mathrm{~cm}$ (n.)", cujos resultados estatísticos foram determinados pelo teste t-student, no mesmo nível de significância.

rurais, tanto no SPO como no SPC, ainda mantém os remanescentes florestais de APP preservados e com ausência de qualquer manejo agroflorestal ou agroextrativista. Segundo Michel Arnold e Ruiz Pérez (2001), o potencial de uso sustentável dos produtos madeireiros e não madeireiros dos componentes florestais realizados pelas comunidades locais mostram que quanto maior o potencial de manejo, menor o uso de insumos nos agroecossistemas, chegando a um ponto em que o produtor deverá decidir se é viável manejar a floresta ou alocar tal esforço em outro componente da propriedade.

Os indicadores ambientais de avaliação sinais de lavra mineral, sinais de poluentes ou poluição e sinais de uso de agrotóxicos não foram identificados nas parcelas de APP avaliadas, tanto no SPO como no SPC. Essa situação demonstra que os produtores de ambos os sistemas de produção não utilizam essas práticas de alto potencial degradador, consideradas crimes ambientais, nas APP.

Quanto aos indicadores ambientais de avaliação relacionados ao estado da cobertura vegetal: presença de animais domésticos, sinais aparentes de erosão, voçoroca ou assoreamento, presença de cultivos anuais, os resultados no SPC apresentaram significativamente maior ocorrência, ou seja, com resultados mais impactantes ao meio ambiente, quando comparados com o SPO (Tabela 3).

Ressalta-se que a presença de animais domésticos e de lavouras com cultivos anuais ou pastagem na APP, além de potencialmente causar erosão e assoreamento dos rios, impedem a regeneração natural da floresta, situação considerada crime ambiental de acordo com o artigo 48 da Lei dos Crimes Ambientais 
TABELA 4: Médias dos indicadores ambientais de avaliação para as áreas de reserva legal (RL) em dois sistemas de produção: orgânico e convencional, de propriedades rurais do Território Portal da Amazônia, norte do Mato Grosso.

TABLE 4: Average results from the environmental evaluation indicators for the legal reserve (RL) area evaluation on both production systems: organic (SPO) and conventional (SPC) on small family farms in Portal da Amazônia territory, Mato Grosso state.

\begin{tabular}{|c|c|c|c|c|}
\hline \multirow{2}{*}{\multicolumn{2}{|c|}{ Indicadores Ambientais de Avaliação (média/ha de RL) }} & \multicolumn{2}{|c|}{ Sistemas de Produção } & \multirow[b]{2}{*}{ Sig.* } \\
\hline & & $\begin{array}{l}\text { Orgânico } \\
\text { (SPO) }\end{array}$ & $\begin{array}{l}\text { Convencional } \\
\text { (SPC) }\end{array}$ & \\
\hline \multicolumn{2}{|l|}{ Árvores cortadas (n.) } & 0,0 & 1,0 & n.s \\
\hline \multicolumn{2}{|c|}{ Frequência absoluta - (parcelas com árvores cortadas, \%) } & 0,0 & 3,3 & n.s \\
\hline \multicolumn{2}{|l|}{ Árvores com DAP > $40 \mathrm{~cm}\left(\mathrm{n}^{\circ}{ }^{\circ}\right)$} & 27,6 & 19,8 & n.s \\
\hline \multicolumn{2}{|c|}{ Frequência absoluta (parcelas com árvores DAP $>40 \mathrm{~cm}, \%$ ) } & 65,0 & 50,8 & sig. \\
\hline \multicolumn{2}{|l|}{ Sinais de fogo ou queimadas recentes $\left(\mathrm{n}^{\circ}{ }^{\circ}\right)$} & 0,0 & 0,0 & n.s \\
\hline \multicolumn{2}{|l|}{ Desflorestamento (área desflorestada, ha) } & 0,01 & 0,02 & sig. \\
\hline \multicolumn{2}{|c|}{ Sinais aparentes de erosão, voçoroca ou assoreamento (ha) } & 0,0 & 0,0 & n.s. \\
\hline \multicolumn{2}{|l|}{ Sinais de lavra mineral (ha) } & 0,0 & 0,0 & n.s. \\
\hline \multicolumn{2}{|l|}{ Sinais de poluentes ou poluição (ha) } & 0,0 & 0,0 & n.s. \\
\hline \multicolumn{2}{|l|}{ Sinais do uso de agrotóxicos (ha) } & 0,0 & 0,0 & n.s. \\
\hline \multirow{3}{*}{ Manejo de produtos madeireiros (ha) } & Preservacionista & 0,87 & 0,98 & sig. \\
\hline & Conservacionista & 0,11 & 0,02 & sig. \\
\hline & $\begin{array}{c}\text { Sistemas } \\
\text { Agroflorestais }\end{array}$ & 0,02 & 0,00 & n.s. \\
\hline \multirow{3}{*}{ Manejo de produtos não madeireiros (ha) } & Preservacionista & 0,92 & 0,98 & sig. \\
\hline & Conservacionista & 0,05 & 0,02 & sig. \\
\hline & $\begin{array}{c}\text { Sistemas } \\
\text { Agroflorestais }\end{array}$ & 0,02 & 0,00 & sig. \\
\hline
\end{tabular}

Em que: * Significância do teste estatístico - médias dos indicadores ambientais de avaliação seguidos de "n.s." não diferem entre si, e seguidos de "sig." diferem entre si, pelo teste Qui-Quadrado em nível de significância de 5\% de probabilidade, à exceção dos indicadores "Árvores cortadas com DAP> $40 \mathrm{~cm}\left(\mathrm{n}^{\circ}\right)$ ", cujos resultados estatísticos foram determinados pelo teste $t$-student, no mesmo nível de significância.

(Lei Federal n. 9.605) (BRASIL, 1998). Segundo Barbosa e Fearnside (2000) em um estudo feito na região Amazônica no Estado de Roraima comparando pastagem com floresta primária em 20\% de declividade, as áreas de pastagem apresentaram em torno de 7,5 vezes mais perda de solo (erosão) em relação a uma área de floresta primária - na ordem de $1.128 \mathrm{Kg} /$ ha.ano -, resultado sobretudo da falta de cobertura do solo e a manutenção permanente de gado na área.

O SPO apresentou parâmetros desejáveis de cobertura do solo significativamente melhores do que o SPC, demonstrando o potencial desse sistema de produção quanto às práticas de conservação do solo. Comparado com o SPC, o solo do SPO apresentou maior cobertura por serapilheira, pequena proporção de solo coberto e a categoria de solo exposto foi quase ausente nas APP. Isto significa que quase metade dos remanescentes florestais da APP no SPC poderiam estar em situação de crime ambiental por "impedir a regeneração natural" da floresta nativa (Lei dos Crimes Ambientais Lei Federal n. 9.605) (BRASIL, 1998).

Essa situação não ocorre apenas na região Amazônica. Silva et al. (2007) estudaram o tipo de manejo utilizado em áreas de matas ciliares de diversas bacias hidrográficas do Estado de São Paulo. Segundo o estudo apenas $16 \%$ das áreas apresentaram a floresta natural remanescente. A maioria das áreas compunha-se de pastagens (51\%) ou com produção agrícola e reflorestamento (22\%). Estes dados demonstram que tais áreas não apenas são desconsideradas para o manejo florestal, mas também estão 
sendo degradadas e suprimidas totalmente para o uso alternativo do solo (agrícola), situação inclusive não permitida pela legislação ambiental brasileira (BRASIL, 1965; 1998).

Os resultados descritos demonstram o maior nível de degradação ambiental nas APP das propriedades rurais no SPC em relação ao SPO, que, além disso, apresentaram remanescentes florestais inferiores ao mínimo exigido pela legislação ambiental, o que requer a recomposição das áreas degradadas segundo o novo Código Florestal Brasileiro (BRASIL, 2012).

Silva et al. (2009) apontam que a vegetação existente às margens dos rios (matas ciliares) promove uma elevada gama de serviços ecológicos essenciais a uma bacia hidrográfica. Os autores consideram estes ecossistemas estratégicos em termos de conservação ambiental, uma vez que a sua degradação desencadeia uma série de consequências ambientais locais e regionais de ordem hidrológica, perda de solo por erosão e perda de biodiversidade. Portanto, o manejo florestal dado a tais ecossistemas torna-se extremamente relevante à manutenção dos serviços ecológicos prestados pelas áreas de matas ciliares ou de várzeas, muito evidentes na Amazônia

\section{Adequação ambiental das RLs}

No caso da reserva legal, a situação não é diferente, como demonstram os resultados da Tabela 4. Foram avaliadas cento e duas (102) parcelas nos remanescentes florestais das áreas de RL, sendo trinta (30) no SPC e setenta e duas (72) no SPO. O próprio número de parcelas avaliadas em cada sistema de produção demonstra maior percentual de áreas florestais no SPO. Além disso, o desflorestamento no SPC foi estatisticamente superior ao SPO, demonstrando a maior fragmentação dos remanescentes florestais de RL existentes no SPC (Tabela 4).

Não houve ocorrência dos indicadores erosão aparente ou assoreamento, sinais de lavra mineral, sinais de fogo, poluentes ou poluição e uso de agrotóxicos sem limitação, tanto no SPO como no SPC (Tabela 4). A frequência absoluta de árvores com DAP $>40 \mathrm{~cm}$ não apresentou diferenças significativas entre os dois sistemas de produção, apesar de o número de árvores por hectare ter sido considerado elevado nos dois sistemas (28 e 20 árvores por hectare, respectivamente no SPO e SPC).

De acordo com Costa e Mitja (2010), os agricultores familiares no Estado do Amazonas apresentam rico conhecimento e saber local sobre os recursos vegetais existentes, principalmente os recursos de natureza medicinal e obtenção de frutos e alimento para a família em sistema de produção agroflorestal. Esses resultados mostram que mesmo com o potencial de uso e manejo, os remanescentes florestais existentes nas propriedades são pouco manejados pelos agricultores, tanto para produtos madeireiros, não madeireiros ou SAFs.

A frequência absoluta de árvores com $D A P>40 \mathrm{~cm}$ foi significativamente superior nas propriedades com SPO, o que significa que as árvores estão mais dispersas, menos concentradas, e presentes na maior parte dos fragmentos florestais, em relação ao SPC. Mediante a análise dos indicadores ambientais de avaliação descritos anteriormente demonstra-se o potencial de manejo de produtos florestais madeireiros e não madeireiros. No entanto, em ambos os sistemas de produção avaliados, os baixos valores de número de árvores cortadas e frequência absoluta de árvores cortadas na RL, sugere o caráter preservacionista do manejo dado pelos agricultores (Tabela 4).

Os resultados do manejo dos produtos madeireiros e dos produtos não madeireiros nas áreas de RL foram significativamente diferentes entre as propriedades rurais dos dois sistemas produtivos (Tabela 4). Nos dois sistemas (SPO e SPC), o manejo preservacionista foi o mais comum, enquanto que o manejo conservacionista e os sistemas agroflorestais foram mais praticados pelos produtores no SPO, sendo que esses foram os únicos que apresentaram SAF nas áreas de RL. Essa situação demonstra que os agricultores orgânicos apresentam uma tendência maior ao uso e conservação das áreas de RL (conservação), enquanto que os agricultores convencionais procuram manter os fragmentos florestais apenas preservados, sem qualquer utilização agroextrativista ou agroflorestal - talvez apenas pela necessidade imposta pelas leis ambientais brasileiras.

De acordo com a legislação ambiental, as áreas de RL são passíveis de intervenção e manejo desde que realizado de forma sustentável, visando manter a proteção e o uso sustentável da vegetação nativa, com respeito aos mecanismos de sustentação do ecossistema (Decreto Federal n. 5.975) (BRASIL, 2006). 
A necessidade de autorização dos Órgãos Ambientais competentes para o manejo florestal (ou agroflorestal) é facultada ao agricultor familiar, sendo permitido o uso doméstico de madeira para lenha (não superior a quinze metros cúbicos por ano) ou para a construção de benfeitorias ou utensílios (em quantidade não superior a dois metros cúbicos por hectare), segundo o novo Código Florestal Brasileiro (Lei Federal n. 12.651) (BRASIL, 2012).

Apesar de as possibilidades previstas pela legislação, a maior parte dos produtores rurais, tanto no SPO como no SPC, ainda mantém os remanescentes florestais preservados com ausência de qualquer uso ou manejo (Tabela 4), ou seja, um potencial pouco explorado.

Segundo Almeida et al. (2007), a floresta amazônica mantém um estoque de recursos com potencial madeireiro e não madeireiro, inclusive com recomendação de algumas espécies potenciais para agricultores familiares de Assentamentos rurais de Santarém - PA. Os autores apontam que o manejo de tais recursos deve ser considerado essencial no planejamento produtivo familiar das comunidades da Amazônia.

Em relação aos sistemas agroflorestais, apesar de terem sido identificados em três propriedades rurais do SPO essa ocorrência deu-se em apenas $2 \%$ das parcelas avaliadas (Tabela 4). Mesmo com o potencial apresentado, os resultados demonstram que os agricultores familiares avaliados, mesmo os produtores orgânicos, pouco utilizam os sistemas agroflorestais como alternativa produtiva da RL e nas APPs.

\section{CONCLUSÕES}

$\mathrm{Na}$ análise de propriedades rurais do Território Portal da Amazônia os indicadores ambientais de avaliação - construídos a partir de aspectos da legislação ambiental vigente - cumpriram com o objetivo de caracterizar e identificar diferenças na qualidade ambiental e no manejo dos remanescentes florestais de RL e APP dos dois sistemas de produção avaliados: orgânico (SPO) e convencional (SPC).

Nas áreas de preservação permanente, o SPO apresentou melhores resultados entre os indicadores ambientais de avaliação relacionados ao estado da cobertura vegetal (desflorestamento e sinais de erosão, assoreamento ou voçoroca). Essa situação reflete os impactos do manejo da pecuária extensiva, avaliada pelos indicadores: presença permanente de animais domésticos (gado) e presença de lavouras com cultivos anuais, nos quais os melhores resultados ocorreram no SPO. Na área de RL, apesar de o desflorestamento ter sido maior no SPC, o indicador sinais aparentes de erosão, voçoroca ou assoreamento não foi identificado em ambos os sistemas de produção.

Os indicadores ambientais de avaliação: sinais de lavra mineral, sinal de poluentes ou poluição, sinal de uso de agrotóxicos e presença de benfeitorias, indicativos de possível crime ambiental pela Lei dos Crimes Ambientais (Lei Federal n. 9.605) (BRASIL, 1998) não foram identificados nas áreas de RL e APP das propriedades rurais avaliadas, em ambos os sistemas de produção. Por outro lado, a ocorrência do indicador desflorestamento foi superior no SPC, tanto nas áreas de RL quanto de APP.

O caráter preservacionista foi predominante no manejo dos remanescentes florestais da RL em ambos os sistemas de produção, seguido pelo manejo conservacionista. Os sistemas agroflorestais foram identificados em três propriedades rurais do SPO e em nenhuma do SPC, o que correspondeu a apenas dois por cento $(2 \%)$ do total de remanescentes florestais avaliados nos dois sistemas de produção. Agricultores do SPO obtiveram melhores resultados em relação ao SPC no que se refere ao indicador ambiental de avaliação: cobertura do solo nas APPs, demonstrando o potencial do SPO quanto à conservação do solo.

Os indicadores ambientais de avaliação construídos a partir da legislação ambiental demonstraram ser uma ferramenta eficiente, prática e de baixo custo, para identificar situações positivas de manejo a serem replicadas ou mesmo situações potencialmente negativas a serem evitadas em relação à legislação ambiental. $\mathrm{O}$ uso dos indicadores ambientais de avaliação pode contribuir no processo de assistência técnica direcionada à adequação à legislação ambiental das propriedades rurais, bem como subsidiar técnicas que visem à sustentabilidade do sistema produtivo das propriedades rurais. Ao ter como indicador de sustentabilidade parâmetros da própria legislação ambiental, o produtor garante tanto a adequação técnica quanto legal de seu processo produtivo. 


\section{REFERÊNCIAS}

ALMEIDA, T. A. et al. Sistemas agroflorestais em áreas de agricultores familiares em Iguapé-Açú-AM: caracterização florística, implantação e manejo. Acta Amazônica, Manaus, v. 37, n. 4, p. 549-558, 2007. ARVOR, D. et al. Analyzing the agricultural transition in Mato Grosso, Brazil, using satellite-derived indices. Applied Geography, Amsterdam, v. 32, p. 702-713, 2012.

BARBOSA, R. I.; FEARNSIDE, P. M. Erosão de solo na Amazônia: estudo de caso na região do Apiaú - RO. Acta Amazônica, Manaus, v. 30, n. 4, p. 601-613, 2000.

BRASIL. Lei Federal n. 10.831, de 23 de Dezembro de 2003. Dispõe sobre a agricultura orgânica e dá outras providências. Diário Oficial da União, Brasília, Seção 1, p. 8.

BRASIL. Lei Federal n. 11.326 de 24 de julho de 2006. Estabelece as diretrizes para a formulação da Política Nacional da Agricultura Familiar e Empreendimentos Familiares Rurais. Diário Oficial da União, Brasília, n. 141, Seção 1, p.1-2.

BRASIL. Lei Federal n. 12.651 de 25 de maio de 2012. Dispõe sobre a proteção da vegetação nativa. Diário Oficial da União, Brasília, n. 102, Seção 1, p.1-8.

BRASIL. Lei Federal n. 12.854 de 27, de agosto de 2013. Fomenta e incentiva ações que promovam a recuperação florestal e a implantação de sistemas agroflorestais em áreas rurais desapropriadas e em áreas degradadas, nos casos que especifica. Diário Oficial da União, Brasília, n. 125, Seção 1, p. 1.

BRASIL. Lei Federal n. 6.938/1981. Disponível em:

$<$ http://www.planalto.gov.br/ccivil_03/leis/L6938.htm>. Acesso em: 13 out. 2011.

BRASIL. Lei Federal n. 9.605 de 12 de fevereiro de 1988. Dispõe sobre as sanções penais e administrativas derivadas de condutas e atividades lesivas ao meio ambiente, e dá outras providências. Diário Oficial da União, Brasília, Seção 1, p. 1.

CONSELHO NACIONAL DO MEIO AMBIENTE (Brasil). Resolução n. 369, de 28 de março de 2006. Dispõe sobre os casos excepcionais, de utilidade pública, interesse social ou baixo impacto ambiental, que possibilitam a intervenção ou supressão de vegetação em Área de Preservação Permanente. Diário Oficial da União n. 61, de 29 de março de 2006, Seção 1, p. 150-151.

CONSELHO NACIONAL DO MEIO AMBIENTE (Brasil). Resolução n. 425, de 25 de maio de 2010. Dispõe sobre critérios para a caracterização de atividades e empreendimentos agropecuários sustentáveis do agricultor familiar, empreendedor rural familiar e dos povos e comunidades tradicionais como de interesse social para fins de produção, intervenção e recuperação de Áreas de Preservação Permanente e outras de uso limitado. Diário Oficial da União, n. 100, de 27 de maio de 2010, p. 53.

CONSELHO NACIONAL DO MEIO AMBIENTE (Brasil). Resolução n. 429/2011, de 28 de fevereiro de 2011. Dispõe sobre a metodologia de recuperação das Áreas de Preservação Permanente. Diário Oficial da União, n. 43, de 02 de março de 2011, p. 76.

CONWAY, G. R. The properties of Agroecosystems. Agricultural Systems, Amsterdam, n. 24, p. 55-117, 1987.

COSTA, J. R.; MITJA, D. Uso de recursos florestais em Manacapuru (AM). Acta Amazônica, Manaus, v. 40, n. 1, p. 49-58, 2010.

D’ANTONA, A.; VANWEY, L.; LUDEWIGS, T. Polarização da estrutura fundiária e mudanças no uso e na cobertura da terra na Amazônia. Acta Amazonica, Manaus, v. 41, n. 2, p. 223-232, 2011.

FEISTAUER, D. Impactos do Novo Código Florestal na regularização ambiental de propriedades rurais familiares. Revista Ciência Florestal, Santa Maria, v. 24, n. 3, p. 749-757, 2014.

FERNANDES, E. M. G. P. Estatística Aplicada. 1. ed. Braga: Universidade do Miho, 1999, 299 p.

FERRAZ, J. M. G. Indicadores de Sustentabilidade: Aspectos Teóricos. In: FERRAZ, J. M. G.; MARQUES, J. F.; SKORUPA, L. A. Indicadores de sustentabilidade em agroecossitemas. Jaguariúna: Embrapa Meio Ambiente, 2003, $281 \mathrm{p}$.

FREITAS, E. P. et al. Indicadores ambientais para áreas de preservação permanente. Revista Brasileira de Engenharia Agrícola e Ambiental, Campina Grande, v.17, n. 4, p. 443-449, 2013.

GARBIN, C. A. S. et al. O papel das universidades na formação de profissionais na área de saúde. Revista da Abeno, São Paulo, v. 6, n. 1, p. 6-10. 2006.

HEINK, U.; KOWARIK, I. What are indicators? On the definition of indicators in ecology and environmental 
planning. Ecological Indicators, Amsterdam, v. 10, p. 584-593, 2010.

IBGE. Disponível em: <ftp://geoftp.ibge.gov.br/mapas/tematicos/mapas_murais/biomas.pdf>. Acesso: 12 ago. 2013. (colocar linkes não quebrados ... todos do IBGE não estão mais ativos)

IBGE. Disponível em: <ftp://geoftp.ibge.gov.br/mapas/tematicos/mapas_murais/clima.pdf>. Acesso: 12 ago. 2013.

IBGE. Disponível em: <ftp://geoftp.ibge.gov.br/mapas/tematicos/mapas_murais/solos.pdf $>$. Acesso: 13 out. 2011.

IBGE. Disponível em: <http:/www.ibge.gov.br/home/estatistica/economia/agropecuaria/censoagro/ brasil_2006/Brasil_censoagro2006.pdf>. Acesso: 12 fev. 2013.

JACOVINE, L. A. G. et al. Quantificação das áreas de preservação permanente e de reserva legal em propriedades da bacia do rio Pomba-MG. Revista Árvore, Viçosa, v. 32, n. 2, p. 269-278, 2008.

KUIPER, J. A checklist approach to evaluate the contribution of organic farms to landscape quality. Agriculture, Ecosystems and Environment, Amsterdam, v. 77, p. 143-156, 2000.

LOPEZ-RIDAURA, S.; MASERA, O.; ASTIER, M. Evaluating the sustainability of complex sócio-environmental system. The MESMIS framework. Ecological Indicators, Amsterdam, v. 2, p. 135$148,2002$.

MACHADO, A. T.; SANTILI, J.; MAGALHÃES, R. A agrobiodiversidade com enfoque agroecológico: implicações conceituais e jurídicas. Brasília: Embrapa Informação Tecnológica, 2008. 98 p.

MEIRELLES FILHO, J. C. O Livro de Ouro da Amazônia. 5. ed. Rio de Janeiro: Ediouro, 2006. 444 p.

MENDES, F. S. et al. Avaliação do uso e cobertura da terra nos anos de 1996, 2006 e 2009 no município de Santa Carmem-MT. In: SIMPÓSIO BRASILEIRO DE SENSORIAMENTO REMOTO, 15., 2011, Curitiba. Anais... Curitiba: INPE, 2011. p. 6434-6441.

MICHEL ARNOLD, J. E.; RUIZ PÉREZ, M. Can non-timber Forest products match tropical Forest conservation and development objectives? Ecological Economics, Amsterdam, n. 39, p. 437-447, 2001.

MOONEM, A. C.; BARBIERI, P. Functional biodiversity: an agroecosystem approach. Agriculture, Ecosystems and Environment, Amsterdam, n. 127, p. 08-20, 2008.

OLIVEIRA, F. S. et al. Identificação de conflito de uso da terra em áreas de preservação permanente no entorno do Parque Nacional do Caparaó, estado de Minas Gerais. Revista Árvore, Viçosa, v. 32, n. 5, p. 899-908, 2008.

ORGANIZAÇÃO DAS NAÇÕES UNIDAS PARA ALIMENTAÇÃO E AGRICULTURA. Sustainable Agriculture and Rural Development (SARD) and Agro-ecology: Policy Brief 11 / ParvizKoohafkan, Jules Pretty, BhuwonSthapit. 2010. Disponível em:

$<\mathrm{ftp}$ //ftp.fao.org/SDA/SDAR/sard/SARD-agroecology\%20-\%20english.pdf>. Acesso em: 10 abr. 2013.

PETERSEN, P. F.; VON DER WEID, J. M.; FERNANDES, G. B. Agroecologia: reconciliando agricultura e natureza. Informe Agropecuário EPAMIG, Belo Horizonte, v. 30. n. 252. p. 7-15, 2009.

SARADÓN, S. J.; FLORES, C. C. Evaluación de la sustentabilidad emagroecosistemas: una propuesta metodológica. Revista Brasileira De Agroecologia, Porto Alegre, n. 4, p. 19-28, 2009.

SILVA, A. M. et al. Análise espaço-temporal da cobertura do solo em faixas de áreas com preservação permanente (APPs) no município de Sorocaba, SP, Brasil. Interdisciplinary Journal of Applied Science, Taubaté, v. 4, n. 2, p. 147-155, 2009.

SILVA, A. M. et al. Historical land-cover/use in different slope and riparian buffer zones in watersheds on the state of São Paulo, Brasil. Scientia Agrícola, Piracicaba, v. 64, n. 4, p. 325-335, 2007.

UBIALLI, J. A. et al. Comparação de métodos e processos de amostragem para estimar a área basal para grupos de espécies em uma floresta ecotonal da região norte matogrossense. Acta Amazônica, Manaus, v. 39, n. 2, p. 305-314, 2009. 